\title{
EL SISTEMA DE CONTROL ELECTORAL EN ALEMANIA
}

\author{
Pablo Fernández de Casadevante Mayordomo
}

SUMARIO: 1. InTRODUCCIÓN. 2. El SISTEMA DE CONTROL ELECTORAL. 2.1. Los órganos electorales de control previo a la celebración de los comicios. 2.1.1. En vía administrativa. 2.1.2. Por el Tribunal Constitucional Federal. 2.2. Control a posteriori sobre la validez de las elecciones al Bundestag. 2.2.1. Control parlamentario. 2.2.2. Control por el Tribunal Constitucional Federal. 3. Conclusiones. 4. BiBliografíA.

\section{INTRODUCCIÓN}

Como bien es sabido, los procesos electorales gozan de una importancia suprema dentro del juego de la democracia, pues «constituyen un instrumento pacífico para producir relevos ordenados en la cúpula del poder que, de otro modo, requerirían de procedimientos más inestables y, probablemente, mucho más expeditivos, como una revuelta, un golpe de Estado o el asesinato del mandatario, episodios, todos ellos, por desgracia demasiado frecuentes a lo largo de la historia» ${ }^{1}$. Y, precisamente porque se trata de procesos que pueden desembocar en una alternancia del poder, las tensiones entre quienes lo detentan y los que aspiran a hacerlo suelen constituir el pan de cada día. Es por este motivo que se antoja fundamental la existencia de un sistema de control electoral que, desde la objetividad, analice y dé respuesta a las distintas controversias que puedan suscitarse en el marco de ese proceso ${ }^{2}$.

1 Pascua Mateo, F., La Administración Electoral, INAP, Madrid, 2007, p. 15.

${ }^{2}$ El mencionado autor habla en Ibid. de «un árbitro que genere la máxima confianza a los contendientes, tanto desde el punto de vista de su competencia técnica como, sobre todo, de su neutralidad política». Estando de acuerdo con él, nosotros añadiríamos al electorado como sujeto que busca también esa confianza. Además, y en relación con la neutralidad política, comprobaremos que, si bien ésta es totalmente deseable, la ausencia de la misma no va necesariamente en detrimento de la credibilidad del órgano de control. 
Dicho lo cual, veremos que el sistema de control electoral alemán es el propio de aquellos Estados en los que la confianza en las instituciones ordinarias $^{3}$ llega hasta el punto de atribuírseles funciones de administración del proceso electoral, incluidas las de resolución de controversias entre los contrincantes. Concretamente, el artículo 41 de la Ley Fundamental de Bonn de 1949 encomienda a un órgano legislativo, el Bundestag ${ }^{4}$, el examen sobre la validez de las elecciones generales, si bien es cierto que será el Tribunal Constitucional Federal -Bundesverfassungsgericht- quien se encargue de resolver de forma definitiva las apelaciones que se le puedan presentar al respecto.

Lo anterior nos lleva a hablar de un sistema mixto creado en 1948, en el que el Parlamento Federal, a través de una Comisión de Verificación Electo$\mathrm{ral}^{5}$-o Wahlprüfungsausschuss - constituye la primera instancia, mientras que la segunda, y última, corresponde al Tribunal Constitucional Federal, que se encarga, como acabamos de señalar, de recibir y resolver en forma firme las posibles apelaciones sobre la validez de las elecciones generales.

Sin embargo, esta forma mixta no ha sido la tónica habitual en la historia del constitucionalismo alemán. De hecho, tanto en la Federación Alemana del Norte, desde 1867, como en el Imperio Alemán, desde 1871, se aplicó un modelo por el cual el Parlamento decidía sobre la validez de las elecciones, acentuándose la independencia del poder legislativo respecto de los otros dos poderes clásicos. No tardó este modelo en ser ampliamente criticado por la alta exposición del mismo a interferencias o influencias por parte de órganos estatales, razón por la cual la Constitución de Weimar de 1919 previó la creación de un Tribunal Electoral, con sede en el propio Parlamento Federal, que se encargara del control de las elecciones. Dicho organismo estaba integrado por dos jueces y tres miembros del Parlamento Federal, y sus decisiones no podían ser impugnadas, lo que propició su fracaso ${ }^{6}$.

3 Véase OSCE, Federal Republik of Germany, Elections to the Federal Parliament (Bundestag) 27. September 2009. OSCE/ODHIR Needs Assessment Mission Report 15-17 july 2009, p. 10, consultado el 12 de febrero de 2014, edición digital, http://www.osce. org/odihr/elections/germany/38397.

${ }^{4}$ El cual, además, decide sobre la pérdida de la condición de miembro de dicha cámara.

5 El nombre completo empleado por el Bundestag en la lista de terminología parlamentaria, que ha traducido al español, es «Comisión de Verificación Electoral, Inmunidades y Reglamento» -visto en http://www.bundestag.de/service/tms_objekte/parlamentsterminologie_spanisch.pdf-.

${ }^{6}$ Además, y como nos recuerda SeIFert, K. H., Bundeswahlrecht, Verlag Vahlen, München, 1976, p. 379, ese Tribunal carecía de competencia para determinar las consecuencias de la invalidez de los comicios, al contrario de lo que, como veremos, sucede con el Bundestag. Más sobre los antecedentes del sistema actual de control electoral en Simm, E., «La calificación de las elecciones por el Parlamento Federal alemán», en Evolución de la Justicia Electoral en México, en Alemania y en España, TEPJF, México, 2003, pp. 115 y 116. 
De este modo, se dio paso al actual método de control, el cual, al atribuir al Parlamento la facultad de calificar inicialmente las elecciones, pone de manifiesto la confianza existente en el poder legislativo para desempeñar de manera objetiva una función tan importante como la que nos ocupa, algo que, por otra parte, sólo puede funcionar en países de contrastada calidad democrática, como en este caso Alemania.

Junto al mecanismo de control sobre la validez de las elecciones generales brevemente descrito, y al que volveremos a referirnos posteriormente, hay que apuntar la existencia de un procedimiento de control previo para la resolución de impugnaciones en relación con determinados actos electorales. Éste es llevado a cabo por una serie de órganos que, aunque en un primer momento pueden recordar a nuestras Juntas Electorales, tienen reconocido un ámbito de competencias mucho más reducido que en el caso de aquéllas.

A continuación, procederemos a desarrollar lo expuesto anteriormente, centrándonos de manera prácticamente exclusiva en el sistema de control previsto para las elecciones generales ${ }^{7}$. No obstante, conviene antes recordar que la configuración de Alemania como República Federal provoca que cada Land cuente con una normativa electoral que, aunque puede diferir en mayor o menor medida de la regulación central ${ }^{8}$, suele inspirarse en la Ley Electoral Federal. Además, los Länder están obligados a respetar los principios electorales de sufragio universal, directo, libre, igual y secreto -artículo 28.1.2 de la Constitución alemana-, lo que, unido al sistema de partidos, garantiza la homogeneidad y transversalidad del sistema electoral ${ }^{9}$. Del mismo modo, hay que tener en cuenta que determinadas competencias que en los comicios federales son atribuidas a unos órganos, corresponderán a otros cuando las elecciones sean de distinto ámbito. Sirva a modo de ejemplo el hecho de que, en los comicios regionales, el Bundestag, que está facultado para calificar en primera instancia las elecciones federales, carece de potestad para examinar la validez de aquéllas, correspondiendo tal función al parlamento regional respectivo ${ }^{10}$.

${ }^{7}$ En el caso de las elecciones a la Presidencia de la República Federal Alemana, el Jefe de Estado es elegido mediante sufragio indirecto por la Asamblea General -Bundesversammlung-, una convención especial constituida expresamente para ello y compuesta por los miembros del Bundestag y un número igual de representantes elegidos por los parlamentos de los diferentes Länder.

${ }^{8}$ Tampoco serán iguales entre sí los regímenes electorales de cada Land.

9 Gómez Varela, C. V. Y Brahms Gómez, J. L., «Alemania», en Corona NaKamuRa, L. A. Y Miranda Camarena, A. J. (comps.), Derecho electoral comparado, Marcial Pons, Madrid, 2012, p. 31.

${ }_{10}$ Normalmente denominados Landtag -en Berlín se llama Abgeordnetenhaus; y en Bremen y Hamburgo, Bürgerschaft-. Un ejemplo de ello lo encontramos en SCHREIBER W., «Landtag, Landtagswahlrecht, Fraktionen, Opposition», en Verfassungshandbuch Sachsen-Anhalt, Nomos, Baden-Baden, 2004, pp. 183 a 186 y, sobre todo, en MiscHAK, 


\section{EL SISTEMA DE CONTROL ELECTORAL}

\subsection{Los órganos electorales de control previo a la celebración de los comicios}

\subsubsection{En vía administrativa}

El artículo 8 de la Ley Electoral Federal-Bundeswahlgesetz- enumera los organismos electorales administrativos ${ }^{11}$ encargados de resolver las quejas e impugnaciones en materia electoral previas a la celebración de las elecciones, variando áquellos en función del objeto de la reclamación.

Al frente de la supervisión de las elecciones federales se sitúa el Director Electoral Federal -Bundeswahlleiter-, designado por el Ministerio Federal del Interior ${ }^{12}$.

Con aquél cooperan los dieciséis directores electorales de los Länder -Landeswahlleiter-, los directores electorales de distrito-Kreiswahlleiter-, los presidentes de las mesas electorales -Wahlvorsteher-y, por lo menos, un presidente electoral y un comité electoral para cada distrito electoral, con la tarea de determinar el resultado de los votos por correo $^{13}$. Estos directores y presidentes -lógicamente, a excepción del Director Electoral Federal- son elegidos por el gobierno del Land en cuestión o por la autoridad designada por él ${ }^{14}, \mathrm{y}$ presiden sus respectivos entes electorales, que son los que veremos a continuación ${ }^{15}$.

Sin embargo, antes es preciso poner de relieve una característica singular de estos órganos electorales, como es la de la capacidad del poder ejecutivo, federal o regional, según el caso, para designar a las personas que ocuparán los puestos directivos de los mismos. Siendo de la opinión de que

J., Die kommunale Wahlprüfung, Schriften zum deutschen und europäischen öffentlichen Recht, Peter Land, Frankfurt am Main, 2008, pp. 227-288.

${ }^{11}$ Los cuales son, en palabras de SCHREIBER W., «Wahlkampf, Wahlrecht und Wahlverfahren», en Parlamentsrecht und Parlamentspraxis, SCHNEIDER, H.P., Y ZEH, W. (dirs), Gruyter, Berlin, 1989, p. 427, los pilares fundamentales sobre los que se sustenta el proceso electoral.

12 Y únicamente legitimado para actuar en los comicios de ese ámbito, además del de las europeas. Tradicionalmente, el puesto de Director Electoral Federal suele ocuparlo el presidente de la Oficina Federal de Estadística.

13 El Director Electoral de Distrito decide cuántos comités se han de constituir para los votos por correo, ello con el fin de constatar el resultado de esa forma de participación electoral el mismo día de los comicios.

${ }_{14}$ Artículo 9.1 Ley Electoral Federal. En cuanto al segundo apartado, establece que es posible nombrar un mismo Director Electoral de Distrito para varios distritos electorales vecinos, así como formar una Comisión Electoral de Distrito conjunta, correspondiendo la decisión en ambos casos al Director Electoral del Land.

15 Artículo 8.1 Ley Electoral Federal. 
ello no es recomendable desde el punto de vista de la imagen de imparcialidad que todo árbitro electoral debe proyectar, es justo apuntar que eso no está perjudicando al correcto funcionamiento de la Administración electoral alemana ${ }^{16}$.

Sea como fuere, y en cuanto al sistema de resolución de las impugnaciones, en la cúspide se encuentra la Comisión Electoral Federal -Bundeswahlausschuss-, compuesta, por un lado, por el mencionado Director Electoral Federal, que la preside, y otros ocho miembros del Bundestag, nombrados por aquél a propuesta de la Cámara Baja, teniéndose en cuenta la representación existente en la misma -artículo 9.2 de la Ley Electoral Federal-. Pero además, y en virtud de la modificación obrada sobre dicho precepto en $2012^{17}$, a esos nueve integrantes se unen dos magistrados del Tribunal Federal Contencioso-Administrativo -Bundesverwaltungsgericht-, que serán igualmente nombrados por el Director Electoral Federal a propuesta del Presidente de dicho Tribunal.

Por su parte, cada Land cuenta con una Comisión Electoral del Land -Landeswahlausschuss-. En cuanto a su composición, éstas se encuentran integradas por el Director Electoral del Land como presidente y seis vocales nombrados por él entre personas titulares del derecho de sufragio, así como por dos magistrados del Tribunal Contencioso-Administrativo de cada Land - Oberverwaltungsgericht ${ }^{18}$. El nombramiento de los miembros de procedencia judicial corresponde igualmente al Director Electoral del Land a propuesta del Presidente de dicho Tribunal.

De esta forma, las reticencias ya apuntadas en relación con la capacidad del correspondiente ejecutivo para designar al Director Electoral Federal o al Director Electoral del Land quedan parcialmente neutralizadas con la presencia de dos jueces, pues ésta contribuye en gran medida a reforzar la imparcialidad de los órganos de control electoral.

Además, cada distrito electoral dispone de una Comisión Electoral de Distrito -Kreiswahlausschuss- compuesta, además de por el Director Electoral del Distrito -Kreiswahlleiter- correspondiente, que será quien la presida, por seis vocales nombrados por él entre aquellas personas que cuenten con derecho a voto.

${ }^{16}$ En España, y aunque no la consideramos como integrante de la Administración electoral, sólo la Oficina del Censo Electoral se incardina en el Instituto Nacional de Estadística, organismo autónomo perteneciente al Ministerio de Economía y Hacienda y cuyo presidente coincidirá con el de aquélla. A la composición de la Administración electoral nos hemos referido en una monografía de próxima publicación, titulada «La Junta Electoral Central».

${ }_{17}$ Concretamente, la reforma se aprueba el 12 de julio de 2012, vía artículo 1 Gesetz zur Verbesserung des Rechtsschutzes in Wahlsachen -BWahlRSchVG-.

18 También en este caso la inclusión de jueces es producto de la reforma del artículo 9.2 Ley Electoral Federal. 
Centrándonos en la forma de elección de los miembros de los organismos electorales ya citados, y en la línea de lo ya señalado en relación con la Comisión Electoral Federal, el artículo 4.2 del Reglamento Electoral Federal -Bundeswahlordnung- establece que la designación de los vocales de los diferentes organismos electorales habrá de llevarse a cabo por los partidos políticos en un orden de prioridad que se corresponderá con los resultados obtenidos por ellos, en el ámbito territorial de que se trate, en las últimas elecciones generales ${ }^{19}$.

En cuanto a las mesas electorales -Wahlvorstände ${ }^{20}$, cada una de ellas se halla constituida por un presidente de mesa, su representante, y por un número de vocales nombrados por aquél, entre personas con derecho a voto, que oscilará ente los tres y los siete -artículo 9.2 Ley Electoral Federal-.

Respecto a la actividad tanto de las comisiones como de las mesas electorales, el artículo 10.1 de la misma norma establece que actuarán, deliberarán y resolverán en sesión pública, señalando, además, que, mientras la citada ley no disponga otra cosa, en las votaciones de dichos órganos las decisiones se adoptan por mayoría simple, correspondiendo al presidente el voto de calidad en caso de empate. Además, los miembros de los órganos electorales, sus representantes y secretarios están obligados a ejercer de forma imparcial sus cargos, y guardar secreto sobre los asuntos que conozcan en sus actividades oficiales.

Por último, cabe señalar que el artículo 9.3 de la Ley Electoral Federal establece la prohibición de ser miembro de más de un órgano electoral.

a) Actos susceptibles de impugnación

En período electoral, sólo determinadas cuestiones pueden ser objeto de reclamación en vía administrativa.

1. Censo electoral: en virtud del artículo 22 del Reglamento Electoral Federal, cabe la posibilidad de impugnar las listas del censo electoral ante la autoridad municipal pertinente-Gemeindebehörde $e^{21}$-, la cual deberá pronunciarse no más tarde del décimo día anterior al de la celebración de los comicios. Contra su resolución podrá interponerse, en el plazo de dos días desde la misma, recurso ante el Director Electoral de Distrito correspondiente, quien tendrá

19 Tal y como se pone de manifiesto en OSCE, Federal Republic of Germany, Elections to the Federal Parliament (Bundestag) 22 September 2013. OSCE/ODIHR Needs Assessment Mission Report 15 july 2013, p. 8, consultado el 6 de marzo de 2014, edición digital, http://www.osce.org/odihr/elections/103583, los partidos políticos entrevistados por esta organización consideran beneficiosa su participación en esas comisiones, afirmando estar, en general, satisfechos con la actuación de la Administración electoral en los distintos niveles.

${ }^{20}$ Una por cada colegio electoral -Wahlbezirk-.

${ }^{21}$ Que son los alcaldes -Bürgemeister-. 
de plazo para resolver hasta el cuarto día anterior a las elecciones, adquiriendo dicha decisión un carácter firme, sin perjuicio de lo que se pueda señalar en un hipotético proceso de revisión de las elecciones -Wahlprüfungsverfahren-.

2. Papeletas electorales: según el artículo 31 del mismo Reglamento, en caso de rechazo de papeletas electorales, cabe la interposición de un recurso ante la autoridad municipal oportuna, que, también en este caso, deberá pronunciarse, como tarde, el décimo día anterior a las elecciones. Contra su resolución cabe, en el plazo de dos días, de nuevo recurso ante el Director Electoral de Distrito correspondiente, el cual habrá de resolver, a más tardar, el cuarto día antes de la celebración de los comicios. Los plazos señalados para la emisión de una resolución, tanto por parte de la pertinente autoridad municipal como del Director Electoral de Distrito, sólo serán exigibles cuando la reclamación inicial se hubiera interpuesto antes del duodécimo día anterior a la celebración de las elecciones.

3. Candidaturas directas ${ }^{22}$ : el artículo 35 del Reglamento Electoral Federal establece que el Director Electoral de Distrito anotará todas las candidaturas de distrito propuestas, indicando el día de su presentación e incluso la hora de la misma en caso de que se produzca los últimos días del plazo establecido al efecto, enviando una copia de la inscripción tanto al Director Electoral del Land como al Director Electoral Federal. A continuación, examinará si dichas propuestas están completas y si se atienen a lo establecido tanto en la Ley Electoral Federal como en el Reglamento Electoral Federal ${ }^{23}$.

Asimismo, y en virtud del artículo 35.3 de dicho Reglamento, en relación con el artículo 25.4 de la Ley Electoral Federal, que atribuye a la Comisión Electoral de Distrito la potestad para eliminar las candidaturas viciadas, ésta deberá acordar de inmediato cuál será la resolución que emita el Director Electoral de Distrito al respecto. A tal efecto, éste presentará ante aquélla todas las candidaturas propuestas, informándole de las conclusiones por él alcanzadas como consecuencia de su examen previo ${ }^{24}$, y tras la sesión, enviará el acta de la misma al Director Electoral del Land y al Director Electoral Federal, informándoles detalladamente de las decisiones adoptadas ${ }^{25}$.

${ }^{22}$ El sistema electoral alemán es mixto -modelo de «representación proporcional personalizada»-, de manera que la papeleta se divide en dos partes. A la izquierda se sitúan las casillas para elegir a un diputado por distrito electoral, mientras que a la derecha se elige, no a un candidato concreto, sino a un partido político. De esta forma, se combina la elección directa de candidatos por distritos electorales con un sistema de representación proporcional.

${ }^{23}$ El artículo 35.2 de esta última norma determina que, en caso de que el Director Electoral de Distrito tenga conocimiento de la inscripción de un mismo candidato en su distrito y en otro diferente, aquél deberá poner dicha circunstancia en conocimiento de su homólogo en el otro distrito.

24 Artículo 36.2 del Reglamento Electoral Federal.

25 Artículo 36.7 del Reglamento Electoral Federal. 
En caso de que alguna candidatura sea rechazada, el artículo 37 del Reglamento Electoral Federal prevé la posibilidad de interponer un recurso ante la propia Comisión Electoral de Distrito en cuestión, siendo su decisión igualmente recurrible ante la Comisión Electoral del Land-el plazo es de tres días desde el pronunciamiento de aquélla $-^{26}$.

4. Listas regionales: el artículo 40 del Reglamento Electoral Federal confiere al Director Electoral del Land la potestad de examinar si las listas regionales están completas y si cumplen los requisitos establecidos tanto en la Ley Electoral Federal como en aquel Reglamento. Antes de proceder al estudio de su validez, el Director Electoral del Land anotará en cada una de ellas el día en que su inscripción haya tenido lugar. Además, hará constar la hora si la presentación tuvo lugar en los últimos días del plazo determinado para ello, debiendo enviar, en cualquier caso, una copia con las solicitudes de inscripción al Director Electoral Federal ${ }^{27}$.

En el supuesto de que exista algún vicio en las listas, el artículo 40.3 del Reglamento Electoral Federal obliga a una aplicación análoga del artículo 35.3 de la misma norma, de manera que la Comisión Electoral del Land deberá determinar de forma inmediata cuál será la resolución que emita el Director de la misma. Para ello, éste pondrá a disposición de dicha Comisión la lista con todas las candidaturas presentadas, indicándole las conclusiones extraídas tras examinarlas $^{28}$. Una vez celebrada la sesión y tomada una decisión, el Director Electoral del Land enviará al Director Electoral Federal una copia del acta de la sesión, adjuntándole la documentación pertinente ${ }^{29}$. En caso de querer impugnar decisiones adoptadas por alguna Comisión Electoral del Land, deberá hacerse ante la Comisión Electoral Federal en el plazo de tres días ${ }^{30}$.

El Director Electoral del Land tiene la obligación de poner en conocimiento del Director Electoral Federal todos los recursos presentados contra las resoluciones de la Comisión Electoral del Land en cuestión, debiendo, además, actuar de conformidad con las instrucciones que éste le proporcione. A continuación, el Director Electoral Federal convoca una sesión para resolver la impugnación, encargándose de transmitir la decisión adoptada por la Comisión Electoral Federal ${ }^{31}$.

26 Artículo 26.2 de la Ley Electoral Federal.

${ }^{27}$ El artículo 40.2 del Reglamento Electoral Federal prescribe que, en caso de que un Director Electoral del Land tenga conocimiento de la inscripción de un mismo candidato en las listas regionales del Land en el que ejerce sus competencias y en las de otro diferente, aquél deberá poner dicha circunstancia en conocimiento del otro Director Electoral del Land.

${ }_{28}$ Primer inciso del artículo 41.2 del Reglamento Electoral Federal, en relación con el artículo 36.2 de la misma norma.

${ }^{29}$ Artículo 41.2 del Reglamento Electoral Federal, segundo inciso.

30 Artículo 28.2 de la Ley Electoral Federal.

31 Artículo 42 del Reglamento Electoral Federal. 
Dicho lo cual, comprobamos que la temática sobre la que deben versar las impugnaciones en vía administrativa antes de las elecciones se encuentra muy acotada. A este respecto, tanto las autoridades electorales como las judiciales han entendido tradicionalmente que, dada la perentoriedad del plazo existente entre la convocatoria de las elecciones y su celebración, sería imposible que, con el fin de evitar consecuencias negativas en la organización del proceso electoral, aquéllas dieran respuesta a tiempo a todas las reclamaciones e impugnaciones que se les presentaran ${ }^{32}$, razón por la cual se estableció ese filtro.

Sin embargo, y tomando como referencia el modelo español ${ }^{33}$, vemos que es factible ampliar la posibilidad de impugnación a algún otro supuesto como, por ejemplo, a los actos de los medios de comunicación de titularidad pública- sin que ello afecte al correcto funcionamiento del sistema. Así lo entendió la misión de la OSCE en 2009, al señalar que, tanto las comisiones electorales de los diferentes Länder, como las de los distritos, recibieron un número relativamente bajo de reclamaciones -entre ellas, algunas sobre el registro de candidatos y de listas regionales, interpuestas ante la correspondiente Comisión Electoral del Land y ante la Comisión Electoral Federal, respectivamente-, siendo todas tramitadas y resueltas con celeridad ${ }^{34}$.

\subsubsection{Por el Tribunal Constitucional Federal}

Pues bien, aunque los supuestos en los que cabe interponer recurso administrativo antes de las elecciones no han variado, existe una importante novedad introducida tras la entrada en vigor del nuevo artículo 18 (4a) de la Ley Electoral Federal ${ }^{35}$. Y es que, desde entonces, frente a la decisión de la Comisión Electoral Federal en relación con la ininterrumpida representación parlamentaria de los partidos políticos -artículo 18.4,

${ }^{32}$ Visto en OSCE, Bundesrepublik Deutschland, Wahl zum deutschen Bundestag 27. September 2009. Bericht der OSZE/ODIHR-Wahlbewertungsmission (Election Assessment Mission) 14. Dezember 2009, p. 22, consultado el 7 de marzo de 2014, edición digital, http:/www.osce.org/de/odihr/elections/germany/40879. Igualmente contrario a dicha ampliación se muestra RотH, G., «Subjektiver Wahlrechtsschutz und seine Beschränkungen durch das Wahlprüfungsverfahren», en Der verfaßte Rechtsstaat, Müller, Heidelberg, 1998, pág, 54.

${ }^{33}$ Del artículo 21.1 de la Ley Orgánica del Régimen Electoral General -LOREG- se desprende que todos los actos electorales son susceptibles de ser recurridos en vía administrativa, salvo cuando la ley electoral «prevea un procedimiento específico de revisión judicial».

${ }^{34}$ OSCE, Bundesrepublik Deutschland, Wahl zum deutschen Bundestag 27. September. Bericht der OSZE/ODIHR-Wahlbewertungsmission (Election Assessment Mission)..., op. cit., p. 24.

${ }^{35}$ Modificación de 19 de julio de 2012. 
apartado 1, número 1 de la Ley Electoral Federal ${ }^{36}$ - y con el reconocimiento de una formación como partido de cara a las elecciones -artículo 18.4, apartado 1, número 2 de la misma norma-, cabe la interposición de un recurso ante el Tribunal Constitucional Federal, cuando antes no era posible. Además, este nuevo precepto viene a complementar la reforma constitucional obrada mediante la redacción del nuevo artículo 93.1 número 4c de la Constitución alemana, el cual dispone que el Tribunal Constitucional Federal se pronunciará sobre los recursos interpuestos por las entidades políticas contra su no reconocimiento como partido político de cara a las elecciones al Bundestag.

Pues bien, esta novedad se nos antoja importantísima, pues lo más conveniente es que la cuestión acerca de la capacidad de una formación para presentarse a unas elecciones quede zanjada antes de la celebración de los comicios, y así lo ha entendido, por fin, el legislador alemán.

En definitiva, con las modificaciones introducidas se ha puesto fin a la imposibilidad que existía hasta ahora de recurrir las decisiones administrativas adoptadas en esos temas, abriéndose, al mismo tiempo, la vía para acudir al Tribunal Constitucional antes de la celebración de los comicios. No obstante, consideramos insuficiente dicha modificación, pues sería conveniente que también fueran recurribles ante los tribunales las resoluciones relativas a las listas regionales o las candidaturas directas, algo que no parece posible en virtud de la legislación vigente ${ }^{37}$.

\subsection{Control a posteriori sobre la validez de las elecciones al Bundestag}

\subsubsection{Control parlamentario}

Como ya señalamos, el artículo 41.1 de la Ley Fundamental de Bonn atribuye a la Cámara Baja el control sobre la validez de las elecciones generales. Dicho procedimiento se encuentra regulado en la Ley de Control Electoral -Wahlprüfungsgesetz-, cuyo artículo 1.1 dispone nuevamente que la competencia para pronunciarse sobre la validez o no de las elecciones parlamentarias corresponde al propio Bundestag, que determinará, en su caso, las consecuen-

${ }^{36}$ La relevancia de este precepto estriba en el hecho de que los partidos políticos que desde las anteriores elecciones hayan contado con al menos cinco escaños en el Bundestag o en un Landtag -Parlamento regional- de forma ininterrumpida, podrán presentar sus candidaturas directas y sus listas regionales sin necesidad de autorización especial ni de firmas de apoyo.

37 En esa línea, OSCE, Federal Republic of Germany, Elections to the Federal Parliament (Bundestag) 22. September 2013. OSCE/ODIHR Election Expert Team Final Report 16 December 2013, consultado el 5 de marzo de 2014, edición digital, http://www. osce.org/odihr/elections/109518, pp. 9 y 10. En contra, Rотн, «Subjektiver Wahlrechtsschutz...», op. cit., pp. 54 y 55. 
cias de esa invalidez ${ }^{38}$. Todo ello, sin perjuicio del recurso que contra las resoluciones de aquél cabe interponer ante el Tribunal Constitucional Federal -artículo 41.2 de la Constitución alemana y artículo 13.3 de la Ley del Tribunal Constitucional Federal -Bundesverfassungsgerichtsgesetz-.

Asimismo, como consecuencia de la reforma del citado artículo 1 de la Ley de Control Electoral ${ }^{39}$, a la facultad examinadora de la validez de las elecciones del Bundestag se le ha de sumar su capacidad para resolver los recursos relativos a la vulneración de ciertos derechos durante la preparación y la celebración de esos comicios, siempre y cuando sean susceptibles del control electoral del artículo 41 de la Carta Magna ${ }^{40}$. Esos derechos serán, principalmente, los de sufragio activo y pasivo previstos en el artículo 38.2 de la misma Norma ${ }^{41}$, siendo la decisión de la Cámara Baja igualmente recurrible ante el Tribunal Constitucional Federal, en virtud de los citados artículos 41.2 de la Constitución alemana y 13.3 de la Ley del Tribunal Constitucional Federal.

Dentro del Bundestag, la labor decisoria se encuentra de facto delegada en la ya aludida Comisión de Verificación Electoral ${ }^{42}$, pese a que el artículo 3.1 de la Ley de Control Electoral solamente señala que dicho organismo «prepara» la decisión del Bundestag ${ }^{43}$. A este respecto, y en virtud del artículo 13.1 de la misma norma, la propuesta de resolución realizada por aquélla deberá ser aprobada por mayoría simple de la Cámara Baja, siendo habitual que el Tribunal Constitucional Federal respalde el criterio adoptado ${ }^{44}$.

38 Artículo 1.2 de la misma norma.

${ }^{39}$ De 19 de julio de 2012.

${ }^{40}$ Por su parte, el apartado segundo de ese artículo 41 establece que, en caso de que se declaren inválidas unas elecciones, deberán señalarse las consecuencias derivadas de ello. A ello hay que añadir, a raíz de la reforma de 12 de julio de 2012, que, cuando durante la preparación o celebración de las elecciones se vulneren los derechos de una persona o de un determinado grupo de personas, el Bundestag deberá reconocer dicha violación aunque las elecciones no hayan sido invalidadas.

${ }^{41}$ Tal y como se señala en el proyecto de Ley para la mejora de la protección de derechos en el ámbito electoral -Entwurf eines Gesetzes zur Verbesserung des Rechtsschutzes in Wahlsachen-, que dio lugar a la reforma electoral.

42 Órgano que, como ya apuntamos y nos vuelve a recordar ZEH, W., «Das Auschußsystem im Bundestag», en Parlamentsrecht und Parlamentspraxis, ScHneIDER, H. P., y ZEH, W. (dirs), Gruyter, Berlín, 1989, p. 1096, es creado, además de para calificar las elecciones, para todo lo relativo a la inmunidad y reglamento interno del Bundestag.

${ }^{43}$ Rauber, D. N., Wahlprüfung in Deutschland: materiell-rechtliche Maßstäbe für die Wahlprüfung bei Parlamentswahlen und Wahlen auf kommunaler Ebene, Nomos, Baden-Baden, 2005, p. 44.

${ }_{44}$ De hecho, tal y como queda puesto de manifiesto en OSCE, Federal Republic of Germany, Elections to the Federal Parliament (Bundestag) 22. September 2013. OSCE/ ODIHR Election Expert Team Final Report..., op. cit., p. 11, el Tribunal Constitucional Federal nunca ha dictado resolución alguna en relación con la asignación de escaños, si 
Ahora bien, en caso de que la decisión final de la Comisión de Verificación Electoral no tenga lugar en tiempo razonable ${ }^{45}$, se podrá prescindir de esta primera instancia y acudir al Tribunal Constitucional Federal ${ }^{46}$. Es importante señalar que, cuando exista alguna duda acerca de la constitucionalidad de cualquier norma electoral, la hipotética declaración de inconstitucionalidad de la misma no le corresponde ni al Bundestag ni a su organismo electoral específico, sino al Tribunal Constitucional Federal ${ }^{47}$.

En cuanto a su composición ${ }^{48}$, y según el artículo 3 de la Ley de Control Electoral, aquella Comisión se encuentra integrada por nueve diputados elegidos por el pleno, nueve sustitutos de los primeros y un asesor por cada grupo parlamentario representado en ella, no siendo estos últimos considerados miembros de la misma. Además, cabe la posibilidad de que una comisión compuesta por miembros de diferentes grupos parlamentarios sin representación en la Comisión de Verificación Electoral nombre a un nuevo integrante de la misma, el cual únicamente gozará de funciones de asesoramiento $^{49}$. En cuanto a la designación del presidente y de su sustituto, será elegido por mayoría simple de entre sus miembros, deshaciendo un hipotético empate el integrante de mayor antigüedad ${ }^{50}$.

Por otro lado, para que dicho órgano pueda aprobar las decisiones que luego serán promulgadas por el Bundestag, y susceptibles, a su vez, de ser recurridas ante el Tribunal Constitucional Federal, se exige mayoría simple y un quórum de constitución de la mitad de sus integrantes ${ }^{51}$.

bien, en ocasiones, ha recomendado al Bundestag la revisión de ciertas previsiones legales en relación con los derechos electorales.

${ }^{45}$ Como señala Horn, H. D., «Muß die Wahlprüfung Sache des Bundestages sein?: überlegungen zu einer überfälligen Revision», en Staat im Wort: Festschrift für Josef Isensee, Müller, Heidelberg, 2007, pp. 424 y 425, ni la Constitución ni la WahlPrG establecen un plazo dentro del cual el Bundestag debe pronunciarse, llegando en la práctica a tardar más de un año en hacerlo. MEYER, H., «Der Überhang und anderes Unterhaltsame aus Anlaß der Bundestagswahl», en Kritische Vierteljahresschrift für Gesetzgebung und Rechtswissenschaft, núm 77, 1994, p. 353, tacha de «escándalo para un Estado de Derecho» la regulación jurídica y aplicación práctica del procedimiento de calificación electoral previsto en el artículo 41 GG. Más en HopPE, W., «Die Wahlprüfungsverfahren durch den Bundestag (Art. 41 Abs. 1 Satz 1 GG)- ein «Wahlprüfungsvehinderungsverfahren?»»), en Deutsches Verwaltungsblatt, $\mathrm{n}^{\circ} .111$, 1996, pp. 344 a 347.

${ }^{46}$ Roth, G., «Zur Durchsetzung der Wahlrechtsgrundsätze vor dem Bundesverfassungsgericht», en Deutsches Verwaltungsblatt, nº 113, Heymann, Köln, 1998, p. 215.

47 SimM, «La calificación de las elecciones...» en op. cit., p. 119.

${ }_{48}$ Que será reflejo de la representación existente en el Bundestag.

49 Artículo 3.2 de la Ley de Control Electoral. Sobre esto, véase LindnER, R., en Orozco-Henríquez, J., (dir.), Electoral Justice: The International IDEA Handbook, International Institute for Democracy and Electoral Assistance, 2010, p. 71.

${ }^{50}$ Artículo 3.3 de la Ley de Control Electoral.

51 Artículo 4 de la Ley de Control Electoral. 
Respecto a la duración del mandato de los miembros de este órgano electoral especial del Bundestag, su coincidencia con la de la legislatura puede dar lugar a una situación controvertida, en tanto en cuanto los nuevos miembros de aquélla deberán decidir sobre la legalidad de unas elecciones que son las mismas que les han aupado a los puestos que ostentan. Así, no sería descartable la aparición de conflictos de intereses que impidieran la objetividad de la decisión a tomar, minando por consiguiente la confianza en el sistema de control electoral ${ }^{52}$.

No obstante, es importante recordar que la regulación llevada a cabo por la Ley de Control Electoral en cuanto a la permanencia en el cargo de los miembros de la Comisión de Verificación Electoral es más proteccionista que la prevista en el artículo 57.2 del Reglamento del Bundestag para los integrantes de las distintas comisiones de esa cámara. Y ello, porque dicho precepto, además de prever el nombramiento de los miembros de las comisiones del Bundestag y de sus sustitutos a cargo de los grupos parlamentarios, reserva a estos últimos un derecho a revocar tal nombramiento, algo que no ocurre en el caso de los integrantes de aquella Junta ${ }^{53}$.

En cuanto a la legitimación para acudir a ella, el artículo 2.2 de la Ley de Control Electoral determina que podrá hacerlo cualquier persona o grupo de personas con derecho a voto ${ }^{54}$, así como cualquier Director Electoral del Land, el Director Electoral Federal -cuando exista un interés público en la calificación de los comicios- ${ }^{55}$, e incluso el Presidente del Bundestag ${ }^{56}$, dentro de los dos meses posteriores a la celebración de las elecciones ${ }^{57}$. Y, para

${ }^{52}$ OSCE, Bundesrepublik Deutschland, Wahl zum deutschen Bundestag 27. September 2009. Bericht der OSZE/ODIHR-Wahlbewertungsmission (Election Assessment Mission)..., op. cit., p. 23.

${ }_{53}$ RAUBER., Wahlprüfung in Deutschland: materiell-rechtliche..., op. cit., p. 45.

${ }^{54}$ Como señala SEIFERT, Bundeswahlrecht, op. cit., p. 382, se incluyen a los partidos políticos, no así a los grupos parlamentarios.

55 Ibid.

${ }_{56}$ Pensado fundamentalmente para las impugnaciones relativas a los mandatos -como apuntamos ya en la nota al pie número cuatro, el Bundestag decide también sobre la pérdida de la condición de parlamentario-.

${ }^{57}$ Tal y como se apunta en OSCE, Federal Republic of Germany, Elections to the Federal Parliament (Bundestag) 22. September 2013. OSCE/ODIHR Election Expert Team Final Report..., op. cit., pp. 10 y 11, la razón que esgrimen las autoridades para no permitir la impugnación de las elecciones con anterioridad a su celebración estriba en que, de ser eso posible, habría de suspenderse todo el proceso electoral hasta que se hubiera resuelto el recurso en cuestión, no siendo ello ni razonable ni proporcional. Y es que, sin ir más lejos, el Bundestag tardó dos años en resolver las 163 reclamaciones interpuestas ante él en relación con las elecciones de 2009. Sobre el objeto de las mismas, véase Deutscher Bundestag, Ausschuss für Wahlprüfung, Inmunität und Geschäftsordnung. Bilanz der Tätigkeit des 1. Ausschusses. 17. Wahlperiode (2009-2013), p. 11, consultado el 13 de marzo de 2014, edición digital, http://www.bundestag.de/bundestag/ausschues- 
poder presentar una impugnación tanto ante la Comisión de Verificación Electoral como ante el Tribunal Constitucional Federal, es imprescindible para su estimación precisar el error electoral en cuestión ${ }^{58}$.

\subsubsection{Control por el Tribunal Constitucional Federal}

Teniendo en cuenta la desconfianza que podría generar dicho control parlamentario, la Constitución de 1949 reserva a un órgano neutral e independiente la decisión final sobre la validez o no de los comicios, compensándose el «error» cometido al atribuir, en primera instancia, dicha competencia al Bundestag ${ }^{59}$. Así, tal y como acabamos de ver, la decisión de la Comisión de Verificación Electoral podrá ser recurrida ante el Tribunal Constitucional Federal, encargándose del asunto, según el artículo 14.2 de la Ley del Tribunal Constitucional Federal, su Sala segunda ${ }^{60}$, la cual decidirá si la decisión adoptada por aquel organismo parlamentario es correcta o no. En este sentido, no cabrá la posibilidad de incluir en el recurso motivos de impugnación no apuntados en el interpuesto ante la citada Comisión ${ }^{61}$.

En cuanto a los sujetos legitimados para recurrir la decisión del Bundestag ante el Tribunal Constitucional Federal, ya sea acerca de la validez de las elecciones generales o sobre la vulneración de derechos aludida, podrá hacerlo un grupo parlamentario, una décima parte de los diputados, así como un particular o grupo de personas. Hasta hace bien poco, para la presentación de un recurso por parte de un individuo -a diferencia de ahora, los colectivos carecían de tal facultad-, era necesaria la presentación de cien firmas de personas con derecho a voto. Sin embargo, dicha exigencia fue eliminada tras la reforma del artículo 48.1 de la Ley del Tribunal Constitucional Federal, como consecuencia, a su vez, de la modificación del artículo 1.1 de la Ley de Control Electoral, el cual, como se ha dicho, autoriza al Bundestag a pronun-

se18/a01/Downloads/Bilanz_des_1_Ausschusses_17_WP.pdf. Por otra parte, el informe OSCE, Federal Republic of Germany, Elections to the Federal Parliament (Bundestag) 22 September 2013. OSCE/ODIHR Needs Assessment Mission Report..., op. cit., p. 8, critica el hecho de que no se publicaran todos los documentos relacionados con esos recursos, con lo que ello conlleva desde el punto de vista de la transparencia.

${ }_{58}$ SimM, «La calificación de las elecciones...» op. cit., p. 118.

59 Isensee, J., «Zwischen Amtsethos und Parteibindung», en Entscheidungen des Parlaments in eigener Sache, Zeitschrift für Parlamentsfragen, $\mathrm{n}^{\circ} .31$, Westdeutscherverlag, Wiesbaden, 2000, p. 421.

${ }^{60}$ Como establece el artículo 2 de la misma norma, el Tribunal Constitucional Federal está compuesto por dieciséis magistrados, los cuales se hallan divididos en dos salas a partes iguales.

${ }^{61}$ SeIFert, K. H., Y Hömig, D., Grundgesetz für die Bundesrepublik Deutschland, Taschenkommentar, Nomos, Baden-Baden, 1991, p. 253. 
ciarse no sólo sobre la validez de las elecciones sino también sobre la vulneración de determinados derechos ${ }^{62}$.

Sobre la valoración que nos merece la exigencia del apoyo de terceras personas para poder impugnar, varía en función de si nos referimos al tiempo anterior a la modificación del artículo 1.1 de la Ley de Control Electoral ${ }^{63} \mathrm{o}$ al momento actual, en el que el objeto de la reclamación puede ser ya un derecho individual. En cuanto al primero, la misión de la OSCE ya había sugerido en 2009 la necesidad de modificar la regla en cuestión, al entender que la potestad de un particular para recurrir a la justicia no debía depender del apoyo de terceros ${ }^{64}$. Sin embargo, en nuestra opinión, si bien es cierto que el hecho de requerir esas cien firmas podía ser considerado como un obstáculo para la eficacia del derecho de impugnación, no ocurría tal cosa en ese contexto, ya que lo que había de dirimirse no era la supuesta violación del derecho de un particular sino la legalidad de las elecciones en $\operatorname{sí}^{65}$. Ello sin perjuicio de que, aunque de manera indirecta, la vertiente subjetiva de este derecho también se viera protegida, si bien en menor medida ${ }^{66}$.

${ }^{62}$ Por su parte, el también modificado artículo 48.3 de la Ley del Tribunal Constitucional Federal dispone que, si del examen de un recurso interpuesto por una persona o un grupo de personas con derecho a voto resulta que ha habido vulneración de sus derechos, el Tribunal Constitucional deberá apreciar dicho extremo pese a que no invalide las elecciones.

${ }^{63}$ Sobre ello también habla Rотн, «Subjektiver Wahlrechtsschutz...», op. cit., p. 56. Como apunta SEIFERT, Bundeswahlrecht, op. cit., p. 76, no están legitimados para ello los partidos políticos.

${ }^{64}$ OSCE, Bundesrepublik Deutschland, Wahl zum deutschen Bundestag 27. September 2009. Bericht der OSZE/ODIHR-Wahlbewertungsmission (Election Assessment Mission)..., op. cit., p. 23.

${ }^{65}$ Es decir, la protección del derecho objetivo. En el mismo sentido, MischaK, J., Die kommunale Wahlprüfung..., op. cit., p. 273.

${ }^{66}$ SCHREIBER, W., «Das Bundesverfassungsgericht als Wahlprüfungsgericht: eine Analyse der jüngeren Wahlprüfungsrechtlichen Spruchpraxis zu Wahlen zum Deutschen Bundestag», en Deutsches Verwaltungsblatt, $\mathrm{n}^{\mathrm{o}}$. 125, 2010, Köln, p. 611. En esa línea, HorN, «Muß die Wahlprüfung...?», op. cit., p. 427; MEYER, H., «Wahlgrundsätze, Wahlverfahren, Wahlprüfung», en Handbuch des Staatsrechts, vol. III, Müller, Heidelberg, 2005, p. 597; RоTH, «Subjektiver Wahlrechtsschutz...», op. cit., pp. 63 a 68; SEIFERT, Bundeswahlrecht, op. cit., p. 77; y SIMM, «La calificación de las elecciones...», op. cit., p. 119 , quien entiende que la verdadera función de la calificación de las elecciones, no es la de «proteger los derechos subjetivos del elector, de los candidatos, o de los partidos», sino que únicamente se trata del «derecho objetivo electoral de asegurar la integración del Parlamento en una forma legal». Por su parte, MischaK, J., Die kommunale Wahlprüfung..., op. cit., pp. 271 y 272, ya discrepaba antes de la reforma, apuntando que la jurisprudencia del Tribunal Constitucional había roto ya, a este respecto, con su posicionamiento tradicional, de manera que el objetivo no era sólo la protección del derecho subjetivo de sufragio. 
De esta forma, era más que probable que, si efectivamente el proceso electoral no se había desarrollado dentro de la legalidad, dichas dudas las mantuviera una pluralidad de personas y no sólo un ciudadano, por lo que la obtención de cien firmas adicionales no debía suponer mayor inconveniente de cara a la impugnación de los comicios ${ }^{67}$. Asimismo, dicho requisito evitaba un uso abusivo de este mecanismo de control por parte de cualquier ciudadano que pudiera estar simplemente descontento con la orientación ideológica de la formación política ganadora. En otras palabras, constituía un filtro que evitaba la acumulación de trabajo para el Bundestag y el Tribunal Constitucional Federal en relación con unas impugnaciones, las relativas a la legalidad de las elecciones, que es fundamental que sean resueltas a la mayor brevedad posible.

En la actualidad, sin embargo, el razonamiento anterior no es del todo válido. Y ello porque, como acabamos de adelantar, tras la modificación de los artículos 1 de la Ley de Control Electoral y 48 de la Ley del Tribunal Constitucional Federal, también determinados derechos subjetivos son objeto de protección tanto por parte del Bundestag como del Tribunal Constitucional Federal. Por este motivo, la exigencia de esas firmas para el reconocimiento del mismo se antojaría excesiva a todas luces, no en cambio en relación con la calificación de las elecciones, donde esa restricción habría podido seguir siendo muy útil de cara a la prevención de una utilización excesiva de esta vía de impugnación de los comicios.

Una vez descrito el sistema de control de las elecciones generales, es de recibo preguntarse acerca de la conveniencia o no del mismo ${ }^{68}$. Pues bien, nosotros entendemos que se corre el riesgo de que el Parlamento carezca de la imparcialidad necesaria para llevar a cabo, por un lado, un control de los requisitos objetivos de legalidad del proceso electoral y, por otro, una adecuada protección de los derechos tanto de los votantes como de los partidos políticos ${ }^{69}$. Por esta razón, estamos con quien afirma que, aunque ésta no es una cuestión nueva, la necesidad de darle una respuesta ha crecido notablemente con el paso del tiempo ${ }^{70}$.

${ }^{67}$ De forma parecida se pronuncia MischaK, J., Die kommunale Wahlprüfung..., op. cit., p. 273.

${ }_{68}$ SIMM, «La calificación de las elecciones...»op. cit., p. 116, pertenece al sector doctrinal minoritario que entiende que la forma actual de calificación de elecciones satisface las exigencias presentes».

${ }^{69}$ ISENSEE, «Zwischen Amtsethos...», op. cit., p. 402 y ss. Sobre la neutralidad en la calificación de los comicios, SCHULTE, M., Y ZEH, W., «Der Auschuß für Wahlprüfung, Immunität und Geschäftsordnung», en SCHNEIDER, H. P. Y ZEH, W. (dir.) Parlamentsrecht und Parlamentspraxis, Gruyter, Berlín, 1989, pp. 1165 y 1166.

${ }^{70}$ Horn, H. D., «Muß die Wahlprüfung Sache des Bundestages sein?: überlegungen zu einer überfälligen Revision», op. cit., p. 423, quien se pregunta sobre la conveniencia de reformar el artículo 41 de la Constitución alemana -el cual establece, como ya se ha 
Un argumento esgrimido a favor del cambio, que sigue la línea de lo apuntado anteriormente, y con el que estamos totalmente de acuerdo, se refiere al hecho de que este control parlamentario establecido en la Constitución choca frontalmente con el principio nemox iudex in causa, por el cual un juez no podrá tomar parte en un proceso en el que tenga intereses personales ${ }^{71}$. A este respecto, aunque nos hallemos fuera del ámbito judicial ${ }^{72}$ y como ya hemos sostenido antes, un parlamentario no debería participar en la calificación de unos comicios cuyo resultado puede apartarle del cargo que ocupa, dado que la valoración que hará de aquéllos es susceptible de verse influenciada por intereses personales y partidistas ${ }^{73}$. $\mathrm{Y}$, por ello, hay autores que entienden que la atribución de la facultad de decisión al Bundestag convierte en previsible su pronunciamiento acerca de la validez de las elecciones ${ }^{74}$, pues se suelen desestimar todas las impugnaciones electorales presentadas ante la Cámara Baja ${ }^{75}$.

Sobre las posibles alternativas a este modelo, HORN realiza una muy interesante exposición de las distintas opciones a seguir. En concreto, nos recuerda cómo un sector doctrinal aboga por traspasar la potestad de calificación de las elecciones a órganos judiciales ${ }^{76}$. No obstante, continúa, volver al modelo instaurado en la República de Weimar -el Tribunal Electoral ya descrito, compuesto por dos jueces y tres parlamentarios- no es una opción, en tanto en cuanto atribuir a un órgano mixto la decisión última sobre la validez de las elecciones iría en contra de lo establecido en el artículo 92 de la Constitución alemana, el cual establece que la potestad jurisdiccional corresponde únicamente a los jueces. De la misma forma, crear al abrigo del

dicho en más de una ocasión, que el control de las elecciones recae en el Bundestag- con el objetivo de poner fin a la crítica descrita.

${ }_{71} \mathrm{Ibid}$. En el mismo sentido se pronuncia ISENSEE, «Zwischen Amtsethos...», op. cit., p. 420 .

72 Aunque, como vemos en Ibid., el proceso que sigue la Comisión de Verificación Electoral para realizar la propuesta de decisión del Bundestag acerca de la calificación de las elecciones ha sido configurado de tal manera que se asemeja a un proceso judicial. En el mismo sentido, KRetschmer, G., «Walhprüfung», en Parlamentsrecht und Parlamentspraxis, dir. SCHNEIDER, H.P., y ZEH, W., Gruyter, Berlín, 1989, p. 441.

${ }_{73}$ Teniendo en cuenta esta circunstancia es entendible la gran demora por parte del Bundestag a la hora de pronunciarse al respecto, y así lo entiende IsENSEE, «Zwischen Amtsethos...», op. cit., p. 421, al preguntarse « ¿por qué deberían darse prisa los diputados?».

74 Horn, «Muß die Wahlprüfung...?», op. cit., p. 424; e IsEnSEe, «Zwischen Amtsethos...», op. cit., p. 420.

75 Al respecto, Ibid., y OSCE, Bundesrepublik Deutschland, Wahl zum deutschen Bundestag 27. September 2009. Bericht der OSZE/ODIHR-Wahlbewertungsmission (Election Assessment Mission)..., op. cit., p. 23.

${ }^{76}$ Horn, «Muß die Wahlprüfung...?», op. cit., p. 435. En esa línea, señala que el hecho de que esta propuesta no haya tenido éxito hasta el momento no es motivo para pensar que no es necesario despojar al Parlamento de tal competencia, estableciendo un sistema más acorde con un Estado democrático como es el alemán. 
artículo $101.2^{77}$ de dicha Norma un tribunal especial fuera del ámbito del Tribunal Constitucional Federal contradiría el principio por el cual dicho órgano ostenta la competencia para conocer de los asuntos estatales. En cuanto a la posibilidad de que dicho tribunal especial estuviera compuesto sólo por miembros del Tribunal Constitucional Federal, también sería de dudosa legalidad en el sentido de que chocaría con la estructura unitaria de dicho órgano y con el principio de dedicación exclusiva de los magistrados que lo integran ${ }^{78}$.

Por otra parte, la hipotética atribución al Presidente de la República de la potestad de calificar en primera instancia las elecciones exigiría la reforma de la Constitución, concretamente del primer inciso del artículo $41.1^{79}$. Del mismo modo, habría que modificar el artículo 41.2 de la Carta Magna, de manera que contra la decisión del Jefe de Estado cupiera la interposición de un recurso ante el Tribunal Constitucional Federal ${ }^{80}$.

Según una parte de la doctrina alemana, la solución pasaría por acabar con el «control en dos niveles» existente en la actualidad y atribuir la facultad de calificación electoral, en exclusiva, al Tribunal Constitucional Federal, opción que es descartada debido a la gran carga de trabajo que padece ${ }^{81}$. No en vano, en 1997 se creó una comisión con el objetivo de proponer soluciones a la pérdida de funcionalidad que dicho órgano sufría como consecuencia de su saturación, señalándose la posibilidad, e incluso conveniencia, de restringir los supuestos en los que cabe acudir a él ${ }^{82}$. Concretamente, aquélla defendió la supresión de la posibilidad de recurrir ante el Tribunal Constitucional Federal las decisiones dictadas por los órganos judiciales de los Länder ${ }^{83}$ en relación con la validez o no de las elecciones regionales.

Al respecto, el Tribunal Constitucional, en las primeras ocasiones en las que se pronunció ${ }^{84}$, reconoció su legitimación para conocer de los recursos interpuestos contra las decisiones dictadas por los diferentes órganos de los Länder en materia electoral, siempre y cuando lo que se estuviera dilucidando fuera si el resultado de las elecciones había sido consecuencia o no de la

${ }^{77}$ Dicho precepto viene a decir que los tribunales especiales sólo podrán ser creados mediante ley.

${ }^{78}$ HorN, «Muß die Wahlprüfung...?», op. cit., p. 435.

${ }_{79}$ El segundo, aún quedando intacto, atribuiría a dicho Presidente la facultad de decidir sobre todo lo relativo a la pérdida de la condición de miembro del Bundestag.

${ }^{80}$ HorN, «Muß die Wahlprüfung...?», op. cit., p. 436.

${ }^{81}$ Ibid.

82 Bundesministerium Der Justiz, Entlastung des Bundesverfassungsgerichts, Bericht der Komission, Verlag, Bonn, 1998, pp. 124 a 126.

${ }^{83}$ Los Landesverfassungsgerichte y Landeswahlprüfungsgerichte.

${ }^{84}$ En Sentencia de 11 de octubre de 1972 -BverfGE 34, 81-, corroborada por Sentencia de 12 de diciembre de 1991 -BverfGE 85, 148-. 
vulneración del derecho a la igualdad -en este caso, universalidad e igualdad del derecho de sufragio-, reconocido en el artículo 3.1 de la Constitución alemana. De esta forma, y a excepción del artículo $38^{85}$ de la misma Norma, aplicable únicamente a las elecciones federales y europeas, ninguno de los demás preceptos constitucionales relativos al voto directo, libre y secreto $^{86}$ sería susceptible de ser invocado como motivo de recurso ante el Tribunal Constitucional, quedando, por tanto, muy limitada la posibilidad de impugnar el resultado de unas elecciones generales ante el Tribunal Constitucional Federal.

Por este motivo, la citada comisión propuso atribuir en exclusiva a los tribunales constitucionales de cada Land la decisión definitiva sobre la validez o no de los comicios celebrados en ese ámbito, de manera que se pudiera denunciar cualquier tipo de vulneración del derecho de sufragio -y no sólo la relativa a la igualdad-, y que la potestad del Tribunal Constitucional Federal quedara limitada al control normativo y a la resolución de impugnaciones contra normas electorales de los Länder. Pues bien, entendemos que esa idea fue respaldada por dicho Tribunal, el cual, en Sentencia de 16 de julio de $1998^{87}$, comenzó señalando que, pese a que el artículo 38 de la Constitución alemana no es, como ya se ha dicho, aplicable a las elecciones de los Länder, su artículo 28 sí declara que los principios fundamentales relativos al carácter universal, directo, libre, igualitario y secreto del voto se encuentran igualmente vigentes en aquéllas, añadiendo que dicha prescripción debe ser respetada en las diferentes regulaciones electorales que se lleven a cabo en el ámbito regional y municipal. Sin embargo, y esto es clave, el Tribunal Constitucional Federal añadió que, pese a lo dicho, el segundo inciso del artículo 28.1 de la Norma Fundamental en ningún caso habilita a los particulares a interponer un recurso ante él.

Asimismo, dispuso en su fallo que, en atención a la autonomía de la que gozan los Länder, y en contraposición a lo tradicionalmente sostenido por su jurisprudencia, se restringe la utilización del artículo 3.1 de la Constitución alemana como vía para acudir al Tribunal Constitucional Federal. De esta forma, y en virtud del ya mencionado artículo 28.1 de dicha Norma, parece claro que cada Land será exclusivamente competente para resolver las impugnaciones que se puedan presentar contra la validez de unas elecciones municipales o regionales. Y, en el segundo párrafo del fallo, se establece que sólo cabrá acudir al Tribunal Constitucional Federal cuando en el Land en cuestión no se haya abierto ninguna vía de impugnación, en cuyo caso, aquél actuará de forma subsidiaria.

${ }^{85}$ Dicho precepto dispone que los miembros del Bundestag serán elegidos por sufragio universal, directo, libre, igualitario y secreto.

${ }^{86}$ Características de ese derecho igualmente mencionadas en el artículo 28 GG, dirigido a los Länder.

${ }^{87}$ BVerfGE 99,17. 
Dicho lo cual, y dejando a un lado esta sentencia que puede gustar más o menos, de lo que no cabe duda es que resulta aconsejable despojar al poder legislativo, de una vez por todas, de la potestad calificadora de las elecciones, atribuyéndola al poder judicial, tal y como sucede en nuestro país ${ }^{88}$. De esta forma, no se arrebataría al Tribunal Constitucional su condición de instancia definitiva en este asunto y todo lo relativo a la calificación de los comicios quedaría en manos de órganos jurisdiccionales ordinarios y constitucionales. El objetivo de ello no es otro que lograr la mayor neutralidad posible a la hora de adoptar una decisión tan trascendental como es la relativa a la validez o no de unos comicios. Además, con el establecimiento de un procedimiento preferente y sumario, podría ponerse fin al gran inconveniente que suele acompañar a todo proceso judicial, el de su enorme dilación ${ }^{89}$.

\section{CONCLUSIONES}

I. La forma en que se encuentra configurado el sistema de control electoral vigente en Alemania responde a la gran confianza existente en el buen hacer de sus instituciones ordinarias, pues éstas ostentan facultades de resolución de determinadas reclamaciones que puedan presentarse en el marco de dicho proceso.

Centrándose el presente trabajo en el modelo de control de elecciones aplicable a las elecciones generales, es preciso apuntar que cada Land cuenta con un régimen que, pese a las diferencias más o menos relevantes que puedan existir con respecto a la regulación central, suele estar inspirado en la Ley Electoral Federal. Asimismo, no debe perderse de vista el hecho de que estos Länder se encuentran en la obligación de respetar los principios electorales de sufragio universal, directo, libre, igual y secreto del artículo 28.1.2 de la Constitución alemana, algo que, unido al sistema de partidos vigente, asegura el carácter homogéneo y transversal del sistema electoral.

II.I. En cuanto al modelo de control electoral previo a la celebración de las elecciones, en la cúspide se halla la Comisión Electoral Federal, compuesta por el Director Electoral Federal como Presidente, ocho miembros del Bundestag y dos magistrados del Tribunal Federal Contencioso-Administrativo. Asimismo, cada Land cuenta con su propia Comisión Electoral, integra-

${ }^{88}$ Sin perjuicio, claro, de las garantías electorales de la jurisdicción constitucional previstas en los artículos 49.3 y 114.2 LOREG.

${ }^{89} \mathrm{Y}$ es que, como afirma HorN, «Muß die Wahlprüfung...?», op. cit., p. 437, «sólo el Derecho rápido es buen Derecho». En este sentido, ROTH, «Subjektiver Wahlrechtsschutz...», op. cit., p. 55 apunta que tal demora afecta a la eficacia del derecho subjetivo a voto, en el sentido de que, si la impugnación electoral es exitosa, la reparación del daño será únicamente ex nunc. Y así, cuanto más se dilate el examen de la validez de los comicios, mayor será la desconfianza en los mismos. 
da por el Director Electoral del Land, que la preside, seis vocales nombrados por él y dos magistrados del Tribunal Contencioso-Administrativo del propio Land, constituyendo la incorporación de estos dos miembros del Poder Judicial, como la de los dos anteriores, un importante reforzamiento de las garantías relativas al proceso electoral. A continuación está la Comisión Electoral de Distrito, compuesta por el Director Electoral de Distrito correspondiente y seis vocales nombrados por él. A todos estos órganos se suman las mesas electorales, cada una de las cuales está compuesta por un presidente de mesa, su representante, y por un número de vocales nombrados por aquél, entre personas con derecho a voto, que oscilará ente los tres y los siete. Por último, y con la misión de determinar el resultado del voto por correo, intervienen, al menos, un Presidente Electoral y un Comité Electoral por cada distrito electoral -artículo 9.2 de la Ley Electoral Federal-.

Dicho lo cual, sorprende el hecho de que todos estos directores y presidentes sean designados directa o indirectamente por autoridades gubernativas, en claro contraste con lo que sucede en nuestro país, donde el Gobierno en ningún caso puede designar a miembros de la Administración electoral -entendiendo que la Oficina del Censo Electoral no forma parte de la misma-. Pero también hay que destacar la incorporación, al estilo de lo que sucede en España, de personas procedentes de la carrera judicial tanto a la Comisión Electoral Federal como a la Comisión Electoral de cada Land, algo inédito hasta la reforma electoral alemana de 12 julio de 2012, y que contribuye a fortalecer la imagen de objetividad e imparcialidad de esos órganos.

II.II. Respecto a los actos susceptibles de recurso antes de la celebración de los comicios, y refiriéndonos, en primer lugar, a la vía administrativa, el abanico de opciones es muy reducido. En concreto, únicamente son impugnables los actos relativos al censo, así como a las papeletas electorales, las candidaturas directas, y las listas regionales -artículos 22, 31, 35 y 40 del Reglamento Electoral Federal, respectivamente- Por ello, somos de la opinión de que sería aconsejable extender a otras materias esa posibilidad -por ejemplo, en relación con los actos de los medios de comunicación de titularidad pública-, no teniendo por qué implicar ello una carga excesiva para el sistema.

En segundo término, y en cuanto a los recursos ante el Tribunal Constitucional Federal, la tradicional imposibilidad de impugnar decisiones y actos de la Administración electoral contrarios a la ley ha sido subsanada, al menos en parte. Y ello, porque la reforma electoral de 2012 introdujo el recurso ante el Alto Tribunal contra las decisiones de la Comisión Electoral Federal, en relación con la exigencia de representación ininterrumpida de los partidos políticos del artículo 18.4, apartado 1, número 1 de la Ley Electoral Federal; y con respecto al reconocimiento de una formación como partido de cara a 
las elecciones -artículo 18.4, apartado 1, número 2 de la misma norma-. Esta última posibilidad también fue prevista mediante la reforma del artículo 93.1 número 4c de la Ley Fundamental de Bonn, obrada ese mismo año.

Pues bien, pese a este avance significativo, somos de la opinión de que la lista de actos y decisiones recurribles ante los tribunales también requiere de una ampliación, por ejemplo, en relación con las decisiones relativas a la aceptación o rechazo de las listas regionales y de las candidaturas directas.

III. Refiriéndonos ahora a las garantías a posteriori, el examen sobre la validez de las elecciones corresponde al Bundestag -que delega tal labor en la Comisión de Verificación Electoral- sin perjuicio, eso sí, de que sus decisiones puedan ser recurridas ante el Tribunal Constitucional Federal, que resuelve de forma definitiva -artículo 41 de la Constitución alemana-. A este respecto, el objeto de control ha dejado de ser estrictamente objetivo, y es que, a la posibilidad de impugnar los comicios ante aquélla, primero, y posteriormente, ante el Tribunal Constitucional Federal, se ha añadido la opción de denunciar ante los mismos órganos la vulneración de ciertos derechos durante la preparación y la celebración de dichas elecciones. Por eso, la eliminación en 2012 de la exigencia de acompañar con cien firmas el recurso contra la decisión del Bundestag nos parece acertada, si bien únicamente en relación con los recursos contra la vulneración de derechos, pues entendemos que dicho requisito constituía un filtro muy útil cuando la reclamación se refería a la validez de los comicios.

En relación con este sistema de control en dos niveles, ya hemos expresado nuestro desacuerdo con el hecho de que sea el Bundestag, órgano con evidentes intereses directos en el asunto, quien en primer lugar deba pronunciarse al respecto, por mucho que la decisión definitiva le corresponda al Tribunal Constitucional Federal.

Un último reproche a realizar es el relativo a la gran dilación en el tiempo que tras las elecciones sufre la tramitación de los recursos, tanto por parte de la Comisión de Verificación Electoral como del Tribunal Constitucional Federal. Y es que, de ser estimado alguno de los recursos interpuestos con posterioridad a las elecciones, no quedaría más remedio que declarar la invalidez de las mismas y convocar unas nuevas para subsanar los vicios observados.

Sea como fuere, y pese a que el sistema de control alemán tiene, a nuestro modo de ver, y como acabamos de señalar, aspectos que deberían ser modificados, es preciso reconocer que su correcto funcionamiento en la práctica está fuera de toda duda. Y en este sentido, tanto la opinión pública alemana como la gran mayoría de los partidos políticos poseen una plena confianza en el correcto proceder de los principales órganos electorales apreciados, por su buena organización, transparencia y eficiencia. 


\section{BIBLIOGRAFÍA}

BundeSMINISTERIUM DER Justiz, Entlastung des Bundesverfassungsgerichts, Bericht der Komission, Verlag, Bonn, 1998.

Deutscher Bundestag, Ausschuss für Wahlprüfung, Inmunität und Geschäftsordnung. Bilanz der Tätigkeit des 1. Ausschusses. 17. Wahlperiode (2009-2013), pág. 11, consultado el 13 de marzo de 2014, edición digital, http://www.bundestag.de/bundestag/ausschuesse18/a01/Downloads/Bilanz_des_1_Ausschusses_17_WP.pdf.

Gómez VArela, C. V. y Brahms Gómez, J. L., «Alemania», en Corona NAKAMURA, L. A. Y Miranda Camarena, A. J. (comps.) Derecho electoral comparado, Marcial Pons, Madrid, 2012 págs. 21-50.

Hoppe, W., «Die Wahlprüfungsverfahren durch den Bundestag (Art. 41 Abs. 1 Satz 1 GG)- ein «Wahlprüfungsvehinderungsverfahren»?», en Deutsches Verwaltungsblatt, núm. 111, 1996, págs. 344-347.

Horn, H.D., «Muß die Wahlprüfung Sache des Bundestages sein?: überlegungen zu einer überfälligen Revision», en Staat im Wort: Festschrift für Josef Isensee, Müller, Heidelberg, 2007, págs. 423-439.

IsEnseE, J., «Zwischen Amtsethos und Parteibindung», en Entscheidungen des Parlaments in eigener Sache, Zeitschrift für Parlamentsfragen, núm. 31, Westdeutscherverlag, Wiesbaden, 2000, págs. 402-424.

Kretschmer, G., «Walhprüfung», en Parlamentsrecht und Parlamentspraxis, dir. Schneider, H.P., y Zeh, W., Gruyter, Berlín, 1989, págs. 441-465.

LINDNER, R., en Orozco-HenríQuez, J., (dir.), Electoral Justice: The International IDEA Handbook, International Institute for Democracy and Electoral Assistance, 2010.

MeYer, H., «Der Überhang und anderes Unterhaltsame aus Anlaß der Bundestagswahl», en Kritische Vierteljahresschrift für Gesetzgebung und Rechtswissenschaft, núm 77, 1994, págs. 312-362.

«Wahlgrundsätze, Wahlverfahren, Wahlprüfung», en Handbuch des Staatsrechts, vol. III, Müller, Heidelberg, 2005, págs. 543-603.

MischaK, J., Die kommunale Wahlprüfung, Schriften zum deutschen und europäischen öffentlichen Recht, Peter Land, Frankfurt am Main, 2008.

OSCE, Federal Republik of Germany, Elections to the Federal Parliament (Bundestag) 27. September 2009. OSCE/ODHIR Needs Assessment Mission Report 1517 july 2009, pág. 10, edición digital, http://www.osce.org/odihr/elections/germany/38397.

- Bundesrepublik Deutschland, Wahl zum deutschen Bundestag 27. September 2009. Bericht der OSZE/ODIHR-Wahlbewertungsmission (Election Assessment Mission) 14. Dezember 2009, edición digital, http://www.osce.org/de/odihr/elections/germany/40879.

Federal Republic of Germany, Elections to the Federal Parliament (Bundestag) 22 September 2013. OSCE/ODIHR Needs Assessment Mission Report 15 july 2013, edición digital, http://www.osce.org/odihr/elections/103583.

- Federal Republic of Germany, Elections to the Federal Parliament (Bundestag) 22. September 2013. OSCE/ODIHR Election Expert Team Final Report 16 December 2013, edición digital, http://www.osce.org/odihr/elections/109518. 
Pascua Mateo, F., La Administración Electoral, INAP, Madrid, 2007.

RAUBER, D. N., Wahlprüfung in Deutschland: materiell-rechtliche Maßstäbe für die Wahlprüfung bei Parlamentswahlen und Wahlen auf kommunaler Ebene, Nomos, Baden-Baden, 2005.

Rотн, G., «Subjektiver Wahlrechtsschutz und seine Beschränkungen durch das Wahlprüfungsverfahren», en Der verfaßte Rechtsstaat, Müller, Heidelberg, 1998, págs. 54-68.

— «Zur Durchsetzung der Wahlrechtsgrundsätze vor dem Bundesverfassungsgericht», en Deutsches Verwaltungsblatt, núm. 113, Heymann, Köln, 1998, págs. 214-219.

SCHREIBER W., «Wahlkampf, Wahlrecht und Wahlverfahren», en Parlamentsrecht und Parlamentspraxis, dir. Schneider, H.P., y Zeh, W., Gruyter, Berlin, 1989, págs. 401-440.

—Das Bundesverfassungsgericht als Wahlprüfungsgericht: eine Analyse der jüngeren Wahlprüfungsrechtlichen Spruchpraxis zu Wahlen zum Deutschen Bundestag», en Deutsches Verwaltungsblatt, núm. 125, 2010, Köln, págs. 609-618.

-LLandtag, Landtagswahlrecht, Fraktionen, Opposition», en Verfassungshandbuch Sachsen-Anhalt, Nomos, Baden-Baden, 2004, págs. 152-202.

SEIFERT, K. H., Bundeswahlrecht, Verlag Vahlen, München, 1976.

SEIFERT, K. H., Y HöMIG, D., Grundgesetz für die Bundesrepublik Deutschland, Taschenkommentar, Nomos, Baden-Baden, 1991.

Schulte, M., Y ZEH, W., «Der Auschuß für Wahlprüfung, Immunität und Geschäftsordnung» en SCHNEIDER, H. P. y ZEH, W. (dir.) Parlamentsrecht und Parlamentspraxis, Gruyter, Berlín, 1989, págs. 1161-1181.

SIMM, E., «La calificación de las elecciones por el Parlamento Federal alemán», en Evolución de la Justicia Electoral en México, en Alemania y en España, TEPJF, México, 2003, págs. 115-122.

ZEH, W., «Das Auschußsystem im Bundestag», en Parlamentsrecht und Parlamentspraxis, dir. Schneider, H.P., y Zeh, W., Gruyter, Berlín, 1989, págs. 1087-1102.

\section{TITLE: The electoral control system in Germany}

RESUMEN: Los procesos electorales desempeñan un papel fundamental en el funcionamiento de cualquier Estado democrático, pues es a través de ellos como se hace posible la alternancia en el poder. En este sentido, y teniendo en cuenta que la lucha por alcanzar tal objetivo suele dar lugar a tensiones y controversias, se antoja primordial la existencia de un sistema de control electoral que vele por el correcto desarrollo de los comicios, dando respuesta a las impugnaciones que por distintos motivos puedan presentarse. El presente trabajo se centra en el modelo de control instaurado en Alemania, principalmente para las elecciones federales, caracterizándose por poseer una configuración propia de aquéllos Estados en los que existe una gran confianza en el correcto proceder de las instituciones ordinarias.

PALABRAS CLAVE: democracia, elecciones, derechos fundamentales, control. 
ABSTRACT: Electoral processes play a key role in the functioning of any democratic State, because it is through them that the alternation of power is possible. In this sense, and considering that the pursuit of this goal often leads to tensions and disputes, a system of electoral control to ensure the proper conduct of the elections seems to be essential responding to challenges that for various reasons may arise. This work focuses on the control model introduced in Germany, mainly for the federal elections, characterized by having their own settings for those States in which there is great confidence in the correct behavior of ordinary institutions.

KEYWORDS: democracy, elections, fundamental rights, control.

RECIBIDO: 26.03.2014

ACEPTADO: 26.05.2014 